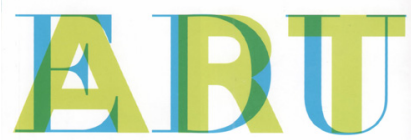

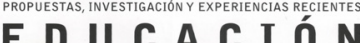

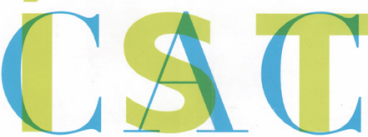

A R T Í S T I C A

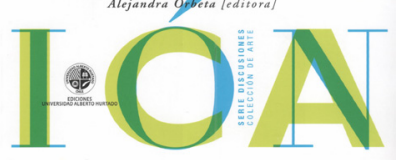

Educación artística. Propuestas, investigación y experiencias recientes

Alejandra Orbeta (ed.)

Año: 2015 Lugar: Santiago de Chile

Ediciones Universidad Alberto Hurtado

Serie Discusiones

Páginas: 332

ISBN: 978-956-357-038-0

\title{
Voces y geografías de la educación artística.
}

Resulta muy necesario afrontar la situación de la educación artística en estos momentos cuando ya contamos con numerosos avances que están llevando a cabo con sus trabajos una gran cantidad de investigadores e investigadoras de todo el mundo. El potencial de nuestra área de conocimiento está todavía por desarrollar, y debemos ir sumando esfuerzos que nos acerquen al terreno de la normalización. Para ello contamos con volúmenes recopilatorios que nos ayudan a observar lo que ocurre en diferentes puntos del planeta. En este caso nos llega desde Chile este recomendable tomo que recoge las ideas y los planteamientos diversos de autores importantes que provienen de diferentes partes de América y Europa.

Lo primero que nos llama la atención de este interesante recopilatorio, editado por Alejandra Orbeta, es la potencia y la capacidad comunicativa de su portada. Felicitar a Gabriel Valdés por esta acertada composición de la "cara" con que se presenta el volumen. Somos educadores e investigadores de artes visuales, por tanto somos especialistas en imagen. Esto requiere tomar un posicionamiento claro cuando damos una imagen (la nuestra) como colectivo. En este trabajo de diseño de Gabriel Valdés destaca el discurso elaborado a partir de la tipografía. Hace décadas que me dedico como artista y como educador a destacar el papel de las letras y los alfabetos como elementos portadores de discurso gráfico (Huerta, 2010), y valoro mucho el trabajo de los buenos diseñadores (Huerta, 2013). En esta portada de libro se ha realizado un juego sencillo pero efectivo (Huerta, 2016). El hecho de que tanto la palabra del nombre "educación" como el adjetivo que la acompaña "artística" dispongan del mismo número de letras (nueve en cada caso) ha permitido a Valdés superponerlas por líneas de tres, consiguiendo así un interesante efecto de tablero que simula el juego del tres en raya, lo cual genera un tránsito de tipo lineal en la visión del conjunto (Huerta, 2011). Al efectuar este entramado tipográfico no solamente consigue un diseño innovador y atractivo, sino que además elimina los tradicionales elementos que suelen acompañar las portadas de los libros de educación artística, como suelen ser las manchas de colores, los lápices, niños 
pintando, visitantes mirando cuadros en un museo, o tantos otros tópicos que ya no aportan nada interesante. Las mayúsculas azules con rasgos encima (o detrás) de las letras de palo permiten la lectura y añaden entusiasmo gráfico a la composición de la portada del libro. Disculpad si me he alargado comentando el diseño de la portada, pero creo que se trata de un buen trabajo, lo cual merece un elogio acorde con su aportación, y en este caso consideraba que valía la pena destacarlo.

El otro gran acierto del volumen es la cantidad de firmas importantes que han participado en él, representando tendencias y posicionamientos diversos de varias nacionalidades, como puedan ser las voces de Imanol Agirre, Ana Mae Barbosa, Rita Irwin, Olga Hubard o LioraBresler, junto a opiniones chilenas que conviene tener muy en cuenta, como es el caso de la propia recopiladora Alejandra Orbeta, o las de Luis Hernán Errázuriz, Natalia Miralles, José Mela, Jaime Martínez, Pilar Díez, Gabriela Carmona, Antonio Silva y Francisca Benavides, algunas de las cuales colaboran habitualmente con el área de Pedagogía en Artes Visuales del Departamento de Arte de la Universidad Alberto Hurtado, entidad que ha propiciado la edición.

Luis Hernán Errázuriz nos indica en su prólogo que este libro constituye un hito relevante en la historia de la enseñanza del arte en Chile. El prologuista considera que la mejora y desarrollo de este campo disciplinar dependerá básicamente de dos factores: la calidad de la educación que imparten las universidades, y el compromiso que asuman los docentes con su formación y desarrollo profesional. Errázuriz apuesta por una formación intelectual sólida y sostenida que promueva la reflexión en torno a las teorías y prácticas de la educación artística, primando la mejora de la calidad. Al revisar los aciertos del volumen, Errázuriz valora positivamente la estructura en cuatro apartados que responden al siguiente esquema: 1) Fundamentos de la educación artística; 2) Investigación en educación artística; 3) Museo y educación artística; y finalmente 4) Propuestas prácticas en educación artística.

En su texto, Alejandra Orbeta repasa las diferentes tendencias que han marcado en las últimas décadas el territorio de la educación en artes. Destaca las reflexiones ya clásicas de SusanneLanger, para quien la educación artística debería contemplar la educación del sentimiento, o los postulados de Herbert Read, según el cual la educación estética en la escuela debería desarrollar las diferentes dimensiones humanas. Tras repasar los nombres habituales de quienes se esforzaron por elevar la educación artística al rango que ha venido adquiriendo (John Dewey, IrenaWojnar, ViktorLowenfeld, Jerome Bruner, ElliotEisner, Howard Gardner, Michael Parsons), sin perder de vista a quienes siguen elaborando discursos innovadores (Fernando Hernández, Paul Duncum, Kerry Freedman), reproduce una tabla con los principales enfoques y perspectivas de la educación artística, para condensar sus conclusiones aludiendo a los acertados planteamientos de Imanol Agirre. Tal y como destaca Alejandra Orbeta, Agirre plantea tres principios sobre los cuales se debería renovar nuestra área: fundamentar la educación artística en la experiencia del sujeto; concebir 
las obras de arte como relatos abiertos condensados de experiencias, y ampliar la educación artística a los artefactos capaces de generar experiencia estética.

En su defensa de la ya clásica "Propuesta triangular", Ana Mae Barbosa asume su posicionamiento culturalista en relación con las políticas artísticas, haciendo énfasis en la lectura (de palabras, gestos, acciones, imágenes, necesidades, deseos, expectativas) ya que la alfabetización para la lectura resulta fundamental para la formación de ciudadanía, situándose en una vertiente humanizadora la lectura de la imagen artística. El concepto de "Abordaje triangular", tal y como lo ha concebido Barbosa, va más allá de las posibles lecturas, y supone una relectura como actividad posible, pero incluso más creativa y problematizadora. Nos recomienda que evitemos la jerarquía de actividades (llegar a la creación tras pasar por la lectura y la contextualización), y del mismo modo que los artistas utilizan procedimientos variados en sus investigaciones visuales, nos anima a diversificar nuestros procedimientos con los estudiantes. Conviene cuestionar, también desde la estética.

Imanol Agirre se nos muestra especialmente lúcido en sus aportaciones. Si bien ya conocíamos su pasión por las ideas de Rorty, Dewey, Bartheso Greene, aquí incide Agirre en el carácter antinormativo del pragmatismo (que proponen algunos de dichos autores), posicionándose de manera crítica ante la tiranía del método, evitando así convertirse en un modelo de explicación de la realidad. Al usar la dialéctica como forma de construcción del conocimiento, destaca el valor que concede el pragmatismo a las formas menos prescriptivas de expresión, como pueda ser la ironía, que nos permite situar nuestra acción educativa en una posición más cercana al modo de operar de las artes. Agirre nos recomienda despojar al arte y sus obras de la dimensión transcendental en la que la tradición moderna las había colocado, pasando a concebir los productos artísticos como relatos abiertos a la investigación creativa. Para Agirre no hay ninguna forma desdeñable, ya que se deben unir esfuerzos y referencias, y por tanto podemos incluir las artes en el mismo universo en el que concebimos la cultura visual, debido a su extraordinario potencial formativo: "no son los objetos de estudio los que deben enfrentarse, sino los modelos formativos desde los que se abordan". Así pues, la estética pragmatista puede ayudarnos a cambiar el foco y dirigir la atención desde el objeto hacia la experiencia que conlleva y propicia. Siguiendo este criterio, que supone un mayor interés hacia la interacción dinámica de significados, descubriremos que lo que realmente nos interesa son las transformaciones de sentido y sus razones, los juegos de poder y las hegemonías que perpetúan o transgreden. Citando a Rorty, argumenta nuestro autor que la actitud ironista supone la práctica constante de la duda. Ironista será quien, en su tarea de conocer, excluye toda pretensión de hacerse con la verdad. Por todo ello, ver obras de arte no supone solamente buscarles un significado, sino verlas a la luz de otras obras de arte, de otros textos, de experiencias pasadas o de experiencias de otras personas. Concluye Agirre que 1 educación en artes debería consistir en generar competencia, criterio y sensibilidad para hacer 
uso de las experiencias que vehiculan las artes o la cultura visual. Y es que mientras cultivamos nuestra identidad, nos estamos haciendo sensibles a los léxicos de otros.

Tras el apartado de fundamentos en el que se incluyen los textos de Agirre, Barbosa. Orbeta y Silva, las aportaciones de Bresler, Irwin, Mela y Benavides se agrupan en un segundo bloque que la editora ha calificado como "Investigación en Educación Artística". La apertura hacia el rol de las emociones está emergiendo como un tema vital dentro de la investigación en artes y educación artística, tal y como nos recuerda LioraBresler, quien hace hincapié en el foco de lo individual, lo cual supone una conexión dialógica, afectiva y cognitiva, algo que nos motiva a ir más allá de nuestros preconceptos. Es más, como señala Denzin, la investigación interpretativa comienza con la biografía y el yo del investigador. A Bresler le preocupa que no destaquen en la investigación cualitativa educativa la práctica del diálogo para lograr la comprensión empática. También los temas éticos resultan clave para Bresler, quien entiende que la yuxtaposición de lo privado y lo público o la empatía que cubra la distancia estética requieren otra forma de pensar la ética. Cobijado por un poderoso apartado de referencias bibliográficas, en un breve epílogo nos confirma su conexión con Burton, Horowitz y Abeles al conceptualizar las competencias desarrolladas mediante el compromiso con el arte como hábitos de la mente, el entramado de la intuición, modos de pensamiento práctico que caracterizan el aprendizaje del arte.

El devenir artográfico al que nos encarama el texto de Rita Irwin parte de la base de que la artografía es una forma de investigación basada en la práctica dentro de las artes y la educación. La artografía transforma la relación tradicional entre teoría y práctica, reconociendo el movimiento encontrado dentro de un rizoma. Los varios "devenires" en los que se basa el relato explicativo de Irwin (devenir intensidad, devenir evento) auspician un modelo de experimentación que la autora ya había expuesto anteriormente. También José Mela valora las aportaciones que traen los métodos artográficos, ya que le han permitido explorar la realidad desde los diferentes intereses y vivencias personales de sus estudiantes, conociendo así sus distintas impresiones y percepciones estéticas. Mela insiste en que conviene aplicar la Investigación Basada en las Artes dentro del sistema educativo chileno, ya que ello contribuirá al fortalecimiento del proceso de enseñanza-aprendizaje de las artes visuales. Por su parte, Francisca Benavides se centra en la parte de la evaluación, un elemento que aborda desde diferentes dimensiones, y teniendo muy en cuenta los anteriores trabajos de Luis Hernán Errázuriz, quien también estuvo siempre pendiente de esta cuestión.

Soy fiel seguidor de Olga Hubard, y me alegra que se traduzca al castellano un trabajo suyo interesantísimo en el que la autora reflexiona sobre el rol del pensamiento crítico que impera en la educación en museos. Se pregunta Hubard hasta qué punto se ha insistido tanto en esta cuestión que se han abandonado otras muchas opciones que permite la experiencia artística en el museo. La autora reivindica la 
posibilidad de experimentar con obras de arte tanto desde la vertiente conceptual como desde la magnitud encarnada, algo que se establece simultáneamente por medio de la razón, los sentidos, las emociones y los canales de respuestas motoras que generamos como personas. Apela a lo pasional, a lo relacionado con el deseo, con lo social, teniendo en cuenta que nuestro sentido de lo que es real comienza $\mathrm{y}$ depende fundamentalmente de nuestros cuerpos. Se lamenta Hubard de que se estén desarrollando sobre todo habilidades de pensamiento racional, lo cual supone abandonar los procesos complejos y multidimensionales por los cuales los humanos conocemos el mundo. Completa el apartado dedicado a la educación en museos un exhaustivo repaso de Natalia Miralles en el que se nos presentan los diversos enfoques que se han venido sucediendo o superponiendo en las últimas décadas.

El volumen se cierra con una interesante miscelánea de propuestas prácticas en educación artística en donde podemos encontrar estrategias que utilizan Gabriela Carmona, Pilar Díez del Corral o Jaime Martínez Iglesias. Y cierro el repaso a lo que nos ofrece esta completa miscelánea recordando los elogios a su portada, unos elogios que extiendo al resto de las aportaciones del libro. Recomiendo, por tanto, su lectura y su difusión. Al fin y al cabo, cada día somos más quienes nos interesamos por estas temáticas.

\section{Referencias bibliográficas}

Huerta, R. (2010) Museo tipográfico urbano. Paseando entre las letras de la ciudad. València: PUV.

Huerta, R. (2011) I Like Cities; Do You Like Letters? Introducing Urban Typography in Art Education, International Journal of Art and Design Education, 29 (1), 72-81.

Huerta, R. (2013) La tipografía en el cine: análisis de cabeceras y créditos de películas como estrategia educativa desde la cultura visual, Archivo de Arte Valenciano, 94, 351-366.

Huerta, R. (2016) The Cemetery as a Site for Aesthetic Enquiry in Art Education, International Journal of Education Through Art, 12 (1), 7-20.

Ricard Huerta. Universitat de València 